\title{
DIFFERENTIAL EFFECT OF FREQUENCY AND DURATION OF MECHANICAL LOADING ON FETAL CHICK CARTILAGE AND BONE DEVELOPMENT
}

\author{
N. Khatib ${ }^{1,}$, C. Parisi ${ }^{1, \S}$ and N.C. Nowlan ${ }^{1,2,3, *}$ \\ ${ }^{1}$ Department of Bioengineering, Imperial College London, London, United Kingdom \\ ${ }^{2}$ School of Mechanical and Materials Engineering, University College Dublin, Dublin, Ireland \\ ${ }^{3}$ UCD Conway Institute, University College Dublin, Dublin, Ireland \\ $\S$ Authors contributed equally to this work
}

\begin{abstract}
Developmental engineering strategies aim to recapitulate aspects of development in vitro as a means of forming functional engineered tissues, including cartilage and bone, for tissue repair and regeneration. Biophysical stimuli arising from fetal movements are critical for guiding skeletogenesis, but there have been few investigations of the biomechanical parameters which optimally promote cartilage and bone development events in in vitro explants. The effect of applied flexion-extension movement frequencies $(0.33$ and $0.67 \mathrm{~Hz})$ and durations ( 2 h periods, 1, 2 or $3 \times$ per day) on knee (stifle) joint cartilage shape, chondrogenesis and diaphyseal mineralisation of fetal chick hindlimbs, cultured in a mechanostimulation bioreactor, were assessed both quantitatively and qualitatively. It was hypothesised that increasing frequency and duration of movements would synergistically promote cartilage and bone formation in a dose-dependent manner. Increasing loading duration promoted cartilage growth, shape development and mineralisation of the femoral condyles and tibiotarsus. While increasing frequency had a significant positive effect on mineralisation, hyaline cartilage growth and joint shape were unaffected by frequency change within the ranges assessed, and there were limited statistical interactions between the effects of movement frequency and duration on cartilage or bone formation. Increased glycosaminoglycan deposition and cell proliferation may have contributed to the accelerated cartilage growth and shape change under increasing loading duration. The results demonstrated that frequencies and durations of applied biomechanical stimulation differentially promoted cartilage and bone formation, with implications for developmentally inspired tissue engineering strategies aiming to modulate tissue construct properties.
\end{abstract}

Keywords: Developmental engineering, tissue engineering, mechanobiology, joint morphogenesis, skeletogenesis, chondrogenesis, mineralisation.

*Address for correspondence: Niamh C. Nowlan, Department of Bioengineering, Imperial College London, London, SW7 2AZ, UK.

Telephone number: +44 2075945189 Email: n.nowlan@imperial.ac.uk

Copyright policy: This article is distributed in accordance with Creative Commons Attribution Licence (http://creativecommons.org/licenses/by-sa/4.0/).

\begin{tabular}{|c|c|c|}
\hline & List of Abbreviations & $\begin{array}{l}0.1 \% \text { Tween } 20 \text { and } 1 \% \text { DMSO in PBS } \\
\text { phosphohistone H3 }\end{array}$ \\
\hline 1TD & once per day & \\
\hline 2TD & twice per day & \\
\hline 3D & 3 dimensional & Introduction \\
\hline 3TD & three times per day & \\
\hline ANOVA & analysis of variance & Healthy skeletal development depends on \\
\hline DAPI & 4',6-diamidino-2-phenylindole & physiological ranges of biomechanical stimuli, \\
\hline DMSO & dimethyl sulphoxide & evident by the range of musculoskeletal conditions \\
\hline GAG & glycosaminoglycans & 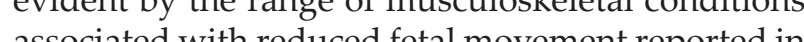 \\
\hline $\mathrm{HF}$ & high frequency & associated with reduced fetal movement reported in \\
\hline $\mathrm{LF}$ & low frequency & clinical cases and in in vivo animal immobilisation \\
\hline OCT & optimal cutting temperature & models (reviewed in Nowlan, 2015). However, \\
\hline OPT & optical projection tomography & the understanding of how type and quantity of \\
\hline PBS & phosphate buffered saline & mechanical stimulation directs cartilage and bone \\
\hline
\end{tabular}


growth during development is unclear. Exploring this question is relevant to the development of new tissue engineering strategies, such as in the 'developmental engineering' paradigm, which aims to recapitulate aspects of in vivo cartilage and bone developmental processes as a means to generate engineered tissues (Freeman and McNamara, 2017; Lenas et al., 2009; Quintana et al., 2009).

Active fetal movements such as whole-body movements, kicking, and stretching subject the developing skeleton to stresses, strains and hydrostatic pressure. Animal studies have shown that limiting fetal movements by inhibiting or immobilising muscle activity leads to altered activity of developmental regulatory genes and skeletal abnormalities such as reduced rudiment length and bone formation, distorted spinal curvature, and abnormal joint cavitation and morphogenesis, highlighting the importance of these forces for normal development (Brunt et al., 2015; Kahn et al., 2009; Levillain et al., 2019; Nowlan et al., 2010a; Nowlan et al., 2010b; Roddy et al., 2011; Rolfe et al., 2013; Sotiriou et al., 2019).

The growth of developing cartilage and bone can be modulated by exposing developing rudiments to controlled biomechanical stimuli ex vivo. Applying hydrostatic pressure to chick fetal femora cultured in a bioreactor enhances endochondral ossification, for which the effect is directly proportional to the frequency of applied stimulus (Henstock et al., 2013). The authors previously showed that the magnitude of physiological movements, in the form of knee flexion-extension cycles, applied to chick hindlimb explants in vitro, influences the development of joint shape in a dose-dependent manner (Chandaria et al., 2016). Furthermore, blocking mechano-sensitive ion channels during culture inhibits the effect of movement on morphogenesis and growth (Parisi et al., 2018).

The influence of a variety of mechanical stimulation techniques on cell-seeded constructs to improve their viability for biological therapies has been widely investigated. The optimisation of loading parameters including magnitude, frequency and duration, has led to improvements in construct criteria such as cell population, matrix organisation and compressive stiffness (Natenstedt et al., 2015; Salinas et al., 2018). Despite this, there are still challenges to overcome with producing functional cartilage and bone constructs with the highly organised structure of native tissues and mechanical properties that can successfully endure full bodyweight-bearing for a lifetime of physical activity (Amini et al., 2012; Choi et al., 2018; Perez et al., 2018).

The crosstalk between tissue engineering and developmental biology has been explored as a means of improving tissue regeneration approaches by mimicking developmental mechanisms regulating cell differentiation and matrix production in skeletal cells and tissues (Freeman and McNamara, 2017; Lenas et al., 2009). For example, studies have attempted to mimic certain aspects of the endochondral ossification process in vitro to improve bone growth, such as formation of a hypertrophic cartilage template (Farrell et al., 2011; Freeman et al., 2015a; Freeman et al., 2015b; Jukes et al., 2008; Scotti et al., 2010; Sheehy et al., 2013) and bone construct neovascularisation (Freeman et al., 2015a; Freeman et al., 2015b; Usami et al., 2009). Furthermore, applying a fixed mechanical stimulation regime to biochemically induced hypertrophic chondrocytes in vitro enhances the osteogenic potential of mesenchymal stem cells more than static culture alone (Freeman et al., 2017). Thus, establishing the type and range of mechanical factors that optimally modulate chondrogenesis and endochondral ossification during development will provide valuable insight into recapitulating the physical environment required for developmental engineering approaches, leading ultimately to enhanced functionality of tissue engineered constructs.

This study aimed to explore the influence and interplay of frequency and duration of mechanical stimulation on chondrogenesis and ossification by culturing fetal chick hindlimbs in an in vitro bioreactor system that mimics physiological flexion. Cartilage growth, morphogenesis and the extent of bone mineralisation were assessed in developing rudiments subjected to regimes of varying frequency and duration of loading. It was hypothesised that both frequency and duration of cyclic flexion loading would enhance chondrogenesis and ossification in a dose-dependent manner. A secondary hypothesis was tested, that frequency and duration of loading are synergistic, in that increasing frequency would enhance the effect of duration on growth, and vice versa. Finally, GAG and collagen deposition and cell proliferation were characterised to investigate the cell- and matrix- level changes underlying any effects of loading regime on hyaline cartilage.

\section{Materials and Methods}

\section{Chick hindlimb explant culture}

All experiments were carried out in line with European legislation (Directive 2010/63/EU). Chick embryos were harvested from white DeKalb eggs (Henry Stewart \& Co, Fakenham, UK), following $7 \mathrm{~d}$ of incubation at $37^{\circ} \mathrm{C}$ under humidified conditions. Hindlimbs were detached from the pelvis and soft tissues were removed as described by Henstock et al. (2013), by gently rolling limbs on filter paper, to improve in vitro viability of the tissues during culture.

Explants were cultured on foam supports over a $6 \mathrm{~d}$ period, as previously employed to study movement regimes on the chick knee (stifle) joint (Chandaria et al., 2016). To summarise, left and right hindlimbs were placed medial side down and pinned through the superior aspect of the pelvis to polyurethane foams cut into rectangular steps (Fig. 1). Foam supports were then placed either 
within bioreactor uniaxial compression chambers with bespoke platens (Ebers TC-3, Ebers, Zaragoza, Spain), for mechanical stimulation groups, or a Petri dish for the static control limbs under the same conditions. All samples were cultured at an air-liquid interface using osteogenic media consisting of alphaminimum essential medium ( $\alpha$-MEM GlutaMAX, Thermo Fisher Scientific) supplemented with $1 \%$ penicillin-streptomycin with amophotericin B, $100 \mu \mathrm{mol} / \mathrm{L}$ ascorbic acid (Sigma-Aldrich), $2 \mathrm{mmol} / \mathrm{L}$ $\beta$-glycerophosphate and $100 \mathrm{nmol} / \mathrm{L}$ dexamethasone. The bioreactor chambers were maintained at $37^{\circ} \mathrm{C}$ and $5 \% \mathrm{CO}_{2}$ in a humidified incubator, with media replenished every $24 \mathrm{~h}$.

\section{Application of mechanical stimulation regimes}

Mechanical stimulation mimicking physiological fetal movements was applied by subjecting hindlimbs to $14^{\circ}\left( \pm 4^{\circ}\right)$ sagittal knee flexion-extension cycles. This degree of flexion was previously found to promote joint cartilage growth, shape development and proliferation in fetal (embryonic day 7) chick hindlimbs (Chandaria et al., 2016), and within the average flexion range observed in ovo (Watson and Bekoff, 1990). Flexion was achieved through cyclic sinusoidal uniaxial deformation of the limb support foams by the loading platens within the bioreactor compression chambers (Fig. 1), as described in detail and captured in videos previously (Chandaria et al., 2016).

To evaluate the independent or combined effect of movement frequency and duration on cartilage and bone formation, hindlimbs were assigned to either a static group, or one of six dynamic loading groups with combinations of duration periods and frequency levels. Dynamic culture limbs were subjected to programmed sinusoidal cyclic loading regimes consisting of two levels of loading frequencies: $0.33 \mathrm{~Hz}$ or $0.67 \mathrm{~Hz}$, and three levels of loading duration: $2 \mathrm{~h}$ stimulation periods applied 1TD, 2TD or 3TD (Table 1, Fig. 2). To place the selected frequencies in an in vivo context, Khaliduzzamana et al., (2019) found that 9- to 10-day old chick embryos exhibit body movements at an average frequency of approximately 30 movements per min $(0.5 \mathrm{~Hz})$. In the case of multiple loading periods, the $2 \mathrm{~h}$ periods were evenly spread across $24 \mathrm{~h}$ (Table 1, Fig. 2).

\section{Specimen numbers and cultures}

A total of 74 fetal chick hindlimbs were harvested for four independent cultures. 2 cultures involved dynamic culture using the $\mathrm{HF}(0.67 \mathrm{~Hz})$ regimes $(2 \mathrm{~h}$ loading steps 1TD, 2TD or 3TD), whilst the other 2 involved dynamic culture using the LF $(0.33 \mathrm{~Hz})$. Static cultures were carried out alongside 2 of the

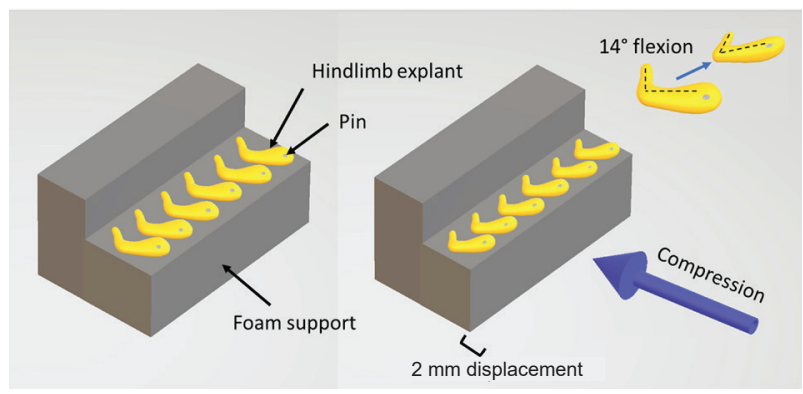

Fig. 1. Schematic representation of the experimental set up for mechanical stimulation of chick hindlimbs. Left and right hindlimbs (only right hindlimbs shown in illustration) were placed medial side down on 45 pore per inch polyurethane foams and pinned down through the superior aspect of the pelvis to avoid damage to the rudiments of interest whilst keeping them in place on the foam. A cyclic $3 \mathrm{~mm}$ compressive displacement was applied to the foam supports placed in the bioreactor chambers to induce a $14^{\circ}\left( \pm 4^{\circ}\right)$ knee joint flexion, as reported by Chandaria et al. (2016). The flexion-extension movement was guided by compressive displacement of the distal limb end by the step, as well as deformation of the foam beneath the limb.

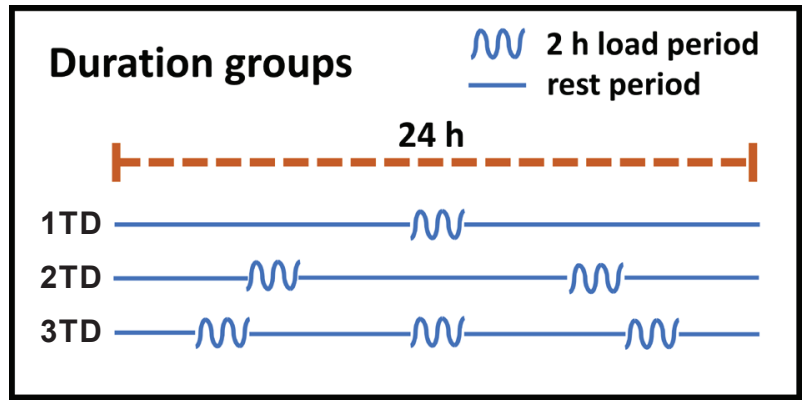

Fig. 2. Schematic representation of the time-line and incidence of loading periods for each experimental group.

Table 1. Summary of movement frequency and duration experimental groups and sample numbers for each analysis and according to tissue type.

\begin{tabular}{|c|c|c|c|c|c|c|}
\hline Group & $\begin{array}{c}\text { Frequency } \\
\text { (Hz) }\end{array}$ & $\begin{array}{c}\text { 2 h load periods } \\
\text { (per day) }\end{array}$ & $\begin{array}{c}n \\
\text { (femur cartilage } \\
\text { measures) }\end{array}$ & $\begin{array}{c}n \\
\text { (tibiotarsus } \\
\text { cartilage measures) }\end{array}$ & $\begin{array}{c}n \\
\text { (femur mineral } \\
\text { measures) }\end{array}$ & $\begin{array}{c}n \\
\text { (tibiotarsus } \\
\text { mineral measures) }\end{array}$ \\
\hline Static & 0 & 0 & 9 & 12 & 12 & 12 \\
\hline LF - 1TD & 0.33 & 1 & 9 & 12 & 6 & 6 \\
\hline LF - 2TD & 0.33 & 2 & 7 & 6 & 6 & 6 \\
\hline LF - 3TD & 0.33 & 3 & 9 & 12 & 6 & 6 \\
\hline HF-1TD & 0.67 & 1 & 10 & 11 & 6 & 6 \\
\hline HF - 2TD & 0.67 & 2 & 7 & 7 & 6 & 6 \\
\hline HF - 3TD & 0.67 & 3 & 11 & 10 & 6 & 6 \\
\hline
\end{tabular}


dynamic cultures. Samples were then pooled together into their respective groups. Explants that were damaged during the culture periods due to limb rotation or dislocation during loading, or during processing post-culture, were removed from the analysis. The final numbers of limbs analysed for each group are described in Table 1.

\section{Quantitative and qualitative assessment of cartilage growth and morphogenesis}

To quantify cartilage growth, measurements were taken from 3D representations of the hindlimb knee (stifle) joints generated through OPT techniques (Sharpe et al., 2002), using protocols previously optimised for imaging embryo development (Quintana and Sharpe, 2011). Prior to OPT, samples were dehydrated in ethanol, stained with $0.055 \%$ alcian blue for $5 \mathrm{~h}$ and cleared in $1 \% \mathrm{KOH}$ for $2 \mathrm{~h}$ at room temperature, permitting selective visualisation of the cartilaginous tissues. Following OPT scans, image projections were reconstructed (NRecon, Micro Photonics Inc., Allentown, PA, USA) and segmented into 3D models (Mimics 19, Materialise, Leuven, Belgium) of the cartilage. Eight knee joint features of the 3D models were measured as illustrated in Fig. 3. Acquiring measurements involved locating the apexes of the anatomical landmarks (Fig. 3) for each model and measuring the point to point distance (3-Matic, Materialise). To qualitatively assess joint cartilage morphogenesis, 3D models were registered using an $\mathrm{N}$-point rigid registration (3-Matic, Materialise). Sagittal shape profiles of the femoral condyles and proximal tibiotarsi were traced, overlaid according to group and visually compared.

\section{Histological and immunofluorescent assessment of chondrogenesis}

Cultured hindlimbs (one or two per loading regime) were processed in a sucrose gradient (15\% then $30 \%$ ) for cryoprotection and then embedded (snap frozen) in an equal-part $30 \%$ Sucrose: OCT medium mix. $10 \mu \mathrm{m}$ cryosections were collected (NX70 Cryostat, Thermo Fisher Scientific, USA) at $-18{ }^{\circ} \mathrm{C}$, fixed in $4 \%$ paraformaldehyde at room temperature and then stored at $-20^{\circ} \mathrm{C}$ until staining. Due to limited sample availability or damage during storage, samples loaded 2TD could not successfully be sectioned or analysed.

To visualise glycosaminoglycans and collagen components in the cartilage matrix, sections were stained with either $1 \%$ toluidine blue for $5 \mathrm{~min}$ or $0.1 \%$ picrosirius red for $30 \mathrm{~min}$, respectively. Following air-drying, sections were visualised using bright-field microscopy (Yenway EX-30, Life Sciences Microscope, Glasgow, UK), and images captured at $10 \times$ magnification at a consistent exposure time of $150 \mathrm{~ms}$. At least two sections from each sample (including when there was more than one sample in a group) were compared for consistency of results, and the highest quality section presented.

Immunofluorescence with labelling of mitosis marker $\mathrm{pHH} 3$ was used to visualise proliferating cells. Three sagittal plane sections through the centre of the femoral lateral condyle from one sample per group were stained and analysed. Sections were first permeabilised with PBST and blocked for $2 \mathrm{~h}$ at room temperature with PBST supplemented with $5 \%(\mathrm{v} / \mathrm{v})$ normal goat serum (Sigma-Aldrich). Next, sections were incubated with a $1: 500$ dilution of primary antibody against $\mathrm{pHH} 3$ (rabbit polyclonal to anti-histone H3 phospho S10 antibody, Abcam, Cambridge, UK) at $4{ }^{\circ} \mathrm{C}$ overnight. The following day, sections were washed with PBST and incubated for $2 \mathrm{~h}$ at room temperature with a $1: 200$ dilution of secondary antibody (goat anti-rabbit Alexa Fluor ${ }^{\circledR} 488$, Abcam). Sections were also incubated with DAPI (Roche Diagnostics GmbH, Germany) at 1 : 1000 dilution for $3 \mathrm{~min}$ to visualise nuclei. Finally, sections
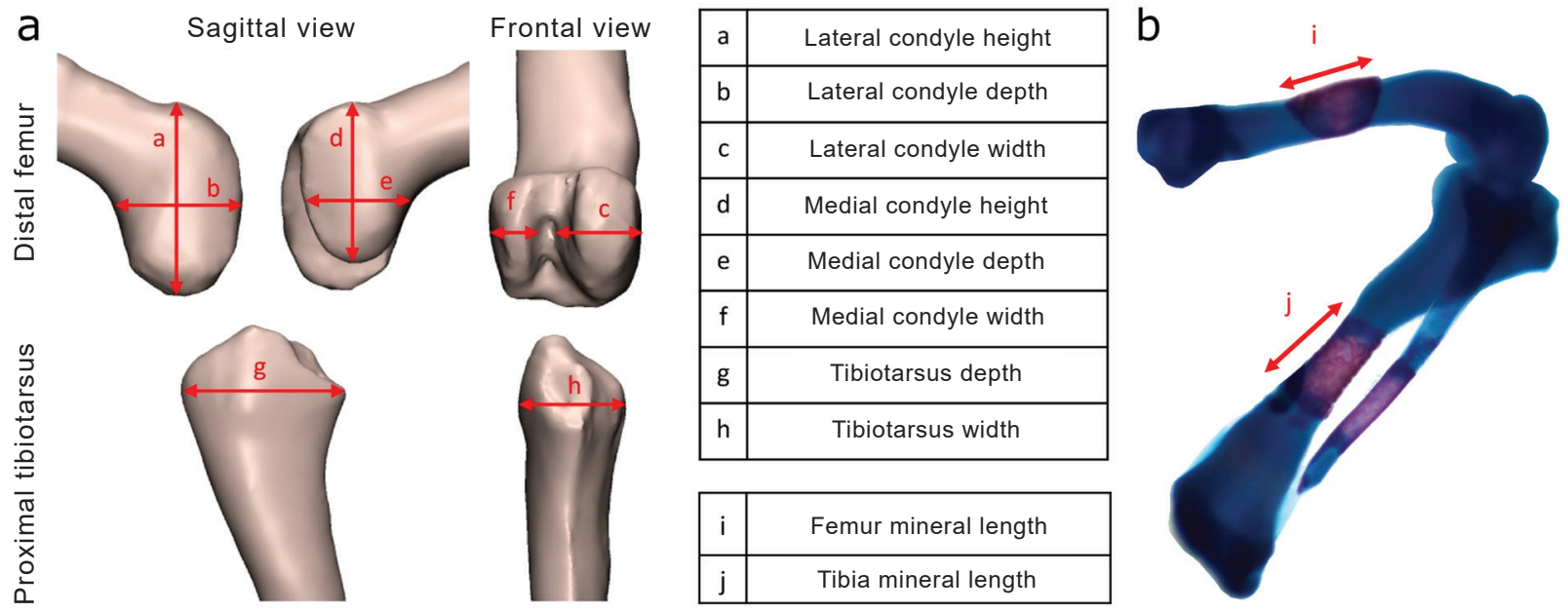

Fig. 3. Knee (stifle) joint cartilage shape features and mineralisation measurements. (a) 8 joint features were measured from generated 3D joint cartilage models (3-matic, Materialise) and (b) two bone mineral measurements measured from light microscope image captures (ImageJ). 
were mounted with anti-fade reagent (ProLong ${ }^{\mathrm{TM}}$ Gold antifade reagent, Life Technologies Co, Waltham, MA, USA) and imaged using a fluorescence microscope (Zeiss LSM 510 inverted). Proliferating cells within the epiphyseal cartilage were counted manually using ImageJ (Image J, Bethesda, MD, USA).

\section{Quantitative assessment of bone mineralisation}

Hindlimbs were stained with $0.01 \%$ alizarin red stain for $2 \mathrm{~h}$ and cleared in $1 \% \mathrm{KOH}$ for $30 \mathrm{~min}$ at room temperature, permitting visualisation of mineralised regions. Alizarin red was poorly retained in the mineralised tissue, preventing the generation of reliable 3D models for analysis of mineralised tissue volume or shape. Therefore, the extent of femoral and tibiotarsal diaphyseal mineralisation was quantified prior to embedding for 3D scanning by measuring the proportion of mineralised tissue against the total length of the femora and tibiotarsi (Fiji, ImageJ) from images taken with an optical microscope (Leica EZ4 HZ).

\section{Statistical analysis}

To explore the influence and interplay of frequency and duration of stimulation on cartilage growth or mineralisation, a two-way ANOVA test was conducted to examine if: (a) there were independent significant effects (main effects) of frequency or duration on cartilage growth or bone mineralisation; (b) whether the effect of load duration on growth or mineralisation was different depending on whether the samples were loaded with low or high frequency (interaction effect); or (c) whether the effect of frequency on growth or mineralisation was different depending on the quantity of loading duration (interaction effect).

Where an interaction effect was present, an interaction contrast test was performed to reveal how a change in loading frequency influences the effect of duration on the measurements. This was achieved by comparison of means testing of the difference between the group mean differences of samples loaded at LF $(0.33 \mathrm{~Hz})$ at short and long durations (1TD vs. 3TD, respectively) and samples loaded at $\mathrm{HF}(0.67 \mathrm{~Hz})$ at short and long durations.

For variables in which the interaction between loading frequency and duration on cartilage or bone measurements was not statistically significant, the significant independent effects (main effects) of frequency and duration were further assessed. Significant independent effects were explored using pairwise group comparisons with Bonferroni corrections, by testing of the unweighted marginal means conducted using Type III sums of squares (IBM SPSS Statistics, US). To interpret directionality of differences, unweighted marginal means with distributions of pooled data were visually assessed in distribution plots ( $R, R$ Core Team). For further interpretation, significant main effect duration and frequency group measurements were compared against static controls by one-way ANOVA tests with Tukey post-hoc tests, also presented in the distribution plots.

\section{Results}

\section{Duration of loading, but not frequency, influences cartilage feature outgrowth}

Four out of eight cartilage joint features were significantly affected by longer movement durations (Table 2), with differences most pronounced in samples loaded 3TD compared to just 1TD (Table 3, Fig. 4a $\mathbf{a}_{\mathrm{i}}-\mathbf{d}_{\mathrm{i}}$ ). Conversely, the two levels of frequency examined did not differentially affect cartilage growth (Table 2, Fig. $\left.4 \mathbf{a}_{\mathrm{ii}}-\mathbf{d}_{\mathrm{ii}}\right)$. Further statistical analyses performed on the four cartilage measurements significantly affected by loading duration revealed that lateral condyle width and height, medial condyle height, and tibiotarsal depth were significantly increased $(p<0.05)$ in samples loaded 3TD relative to 1TD (Table 3, Fig. $\left.4 \mathbf{a}_{\mathrm{i}}-\mathbf{d}_{\mathrm{i}}\right)$. Lateral condyle height and tibiotarsal width displayed the most prominent responses to loading duration, with $11.3 \%$ and $19 \%$ increases in mean measurements, respectively. The progressive trend of the effect of longer loading durations on growth was also evident in comparisons between loaded groups and static controls (Fig. $4 \mathbf{a}_{\mathrm{i}}-\mathbf{d}_{\mathrm{i}}$ ). Loading samples 2TD or 3TD, but not 1TD, led to significant increases in lateral condyle width compared to static samples (Fig. $\left.4 \mathbf{a}_{\mathrm{i}}\right)$, whereas the tibiotarsal depth was significantly increased only when loaded 3TD compared to static samples (Fig. $4 \mathbf{d}_{\mathrm{i}}$ ). This effect was not pronounced for adjacent pairwise duration groups, except for significant differences between samples loaded 2TD and 3TD for the lateral condyle height and tibiotarsal depth (Table 3, Fig. $4 \mathbf{b}_{\mathbf{i}^{\prime}} \mathbf{d}_{\mathrm{i}}$ ). The effect of duration on growth did not appear to plateau at the longest duration period.

The outcome of enhanced cartilage growth with increased loading duration was also observed in the qualitative analysis of joint shape outlines. Most notably, femora loaded 3TD (Fig. 5d,g) displayed increased lateral condyle width and height compared to other duration groups, and static controls (Fig. 5a-c,e,f). Loading 3TD led to enhanced medial condyle posterior curl outgrowth (Fig. 5k,n) particularly when compared to samples loaded 1TD and static controls (Fig. 5h,i,l). In samples exposed to the longest loading durations, the tibiotarsal plateau was deeper, due to more pronounced anterior and posterior protrusions (Fig. 5r, u) and showed more varied shape profiles within the group compared to within other groups (Fig. 5o-q, $\mathbf{s , t}$ ). In contrast, comparison of shape profiles between LF and HF groups did not reveal any clear differences, except for an increased number of samples exhibiting enlarged tibiotarsal posterior protrusions in samples loaded at HF 3TD (Fig. 5u) relative to the LF equivalent (Fig. 

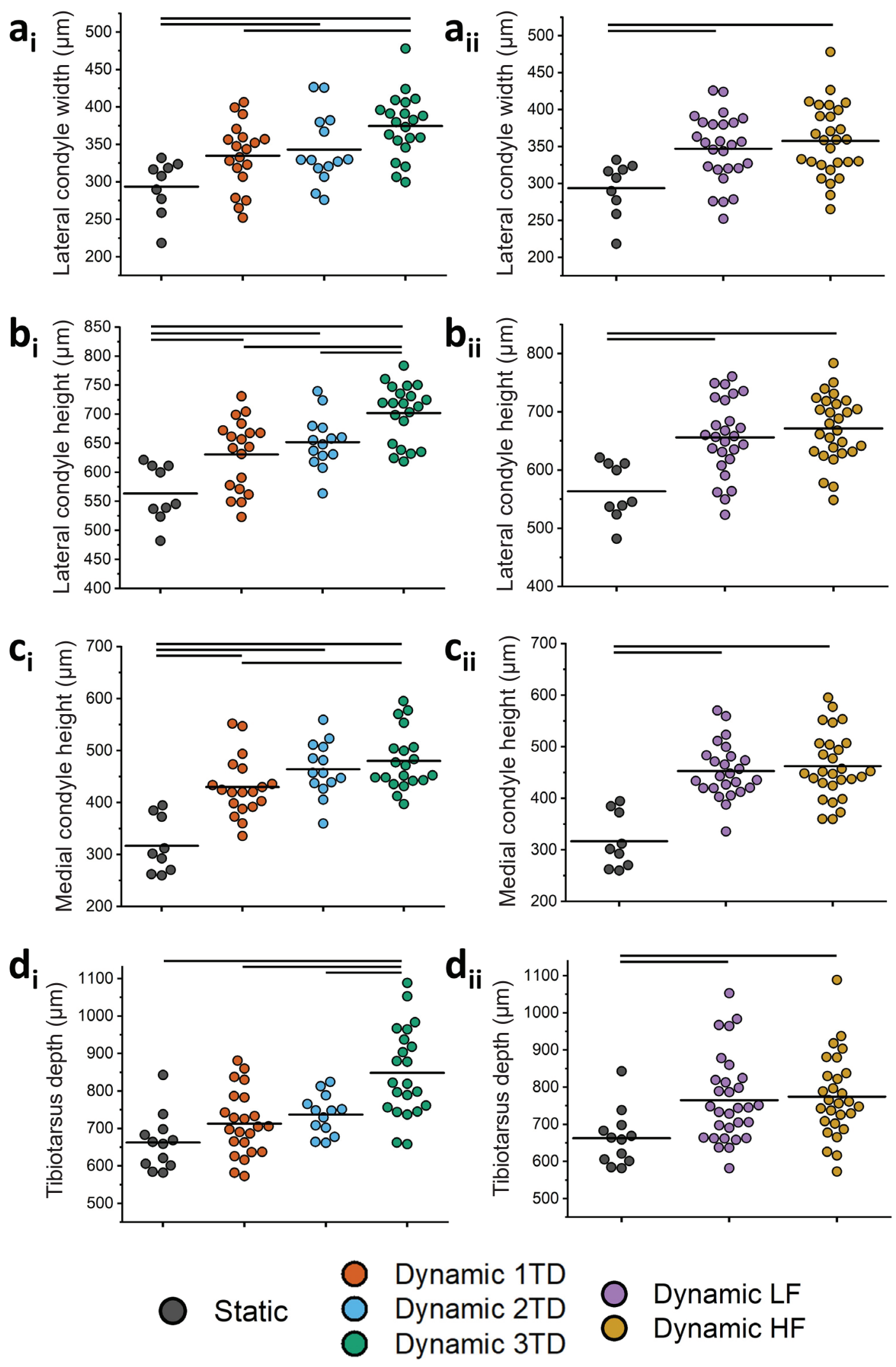

Fig. 4. Increased loading duration, but not loading frequency, led to statistically significant differences in progression of joint cartilage feature growth. Comparison of significantly affected joint feature measurements as analysed in the two-way ANOVA (Table 2), pooled according to loading duration groups $\left(\mathbf{a}_{\mathbf{i}}-\mathbf{d}_{\mathbf{i}}\right)$ or loading frequency groups $\left(\mathbf{a}_{\mathrm{ii}}-\mathbf{d}_{\mathrm{ii}}\right)$, with static cultured sample measurements for comparison. Duration groups include samples dynamically loaded for $2 \mathrm{~h}$ periods 1TD (orange), 2TD (blue) or 3TD (green) $\left(\mathbf{a}_{\mathrm{i}}-\mathbf{d}_{\mathrm{i}}\right)$. Loading frequency groups include samples loaded at LF (purple) or HF (gold) $\left(\mathbf{a}_{\mathrm{ii}}-\mathbf{d}_{\mathrm{ii}}\right)$. Central bars represent group means and bars above represent significant differences between groups $(p<0.05)$. 


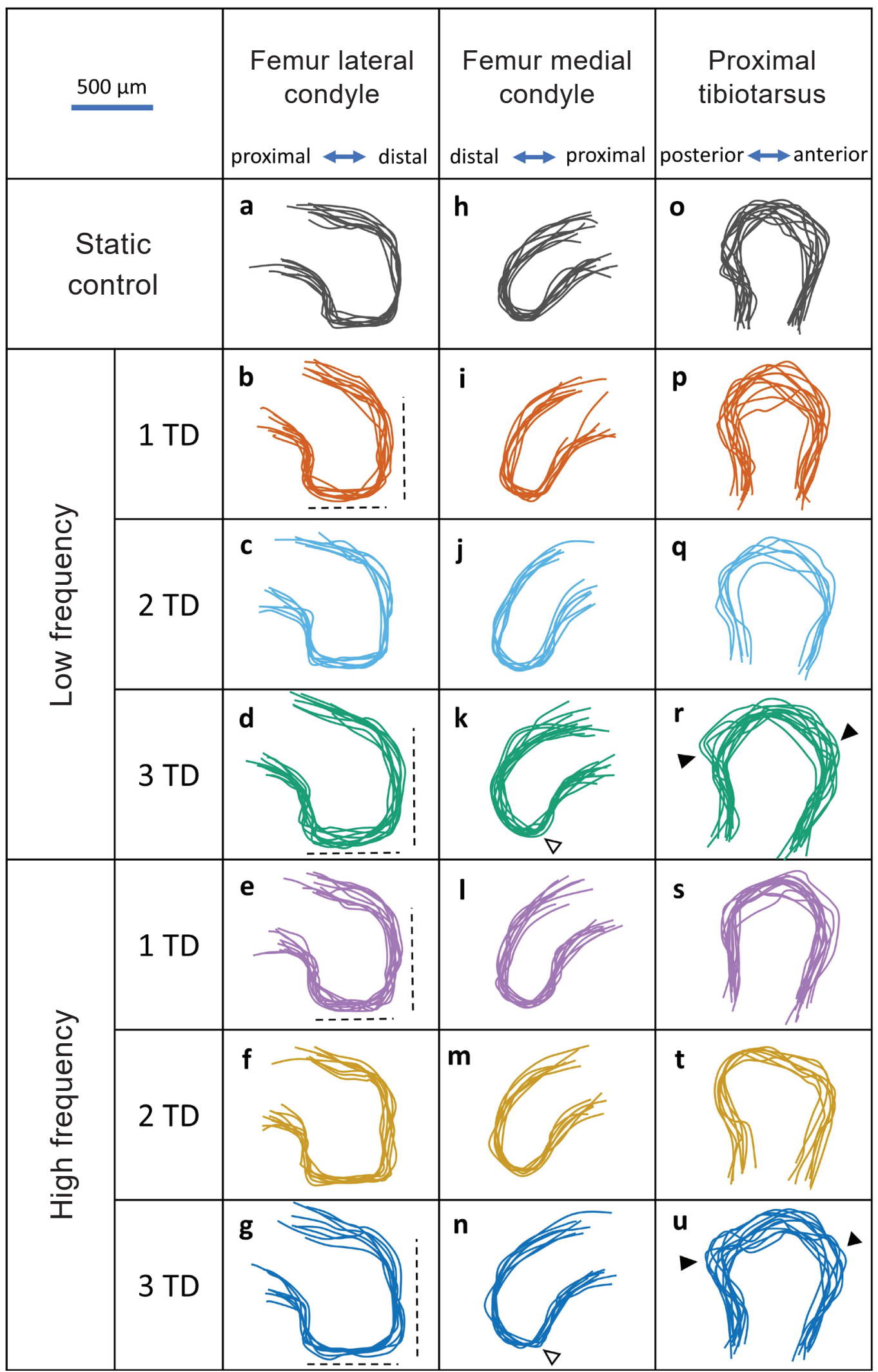

Fig. 5. Joint cartilage morphogenesis was visibly promoted by increased loading duration, but not by frequency of loading. Limbs loaded for longer durations (3TD) displayed taller and deeper lateral femoral condyles $(\mathbf{d}, \mathbf{g})$, extended medial condyle posterior curls $(\mathbf{k}, \mathbf{n})$ and deeper tibiotarsal plateaus with extended anterior and posterior protrusions $(\mathbf{r}, \mathbf{u})$ compared to shorter durations (1TD) and static controls. Traces represent sagittal shape profiles of 3D distal femur and proximal tibiotarsus models for samples loaded for $2 \mathrm{~h}$ periods 1TD, 2TD and 3TD, and at LF or HF. Dotted lines: horizontal, lateral condyle depth; vertical, lateral condyle height; Hollow arrows: extended posterior curl in medial femoral condyles; Solid arrows: extended anterior and posterior protrusions of tibiotarsus plateaus. 
5r). However, this difference was not statistically captured by the quantitative analysis of tibiotarsal depth.

Increasing duration of loading promotes GAG synthesis and cell proliferation in the femoral lateral condyle

Limbs loaded 3TD displayed apparent increases in GAG synthesis throughout the lateral condyle compared to those loaded 1TD and non-loaded limbs (Fig. 6). This was particularly evident with comparison of the central and proximal aspects of the femoral condyles between groups.. Altering loading frequency did not reveal any clear observable effect on GAG deposition (Fig. 6). For limbs loaded 3TD, the strongest GAG deposition was localised to the articulating cartilage surfaces (anterior and distal aspects) (Fig. 6, black arrows).

Dynamically loaded samples displayed increased collagen synthesis at the anterior and distal aspects of the articular surfaces and in the perichondrium of the lateral condyles when compared to statically cultured samples (Fig. 7, hollow arrows). There were no obvious differences apparent in epiphyseal collagen synthesis under the various loading regimes (Fig. 7). However, the collagen matrix appeared denser around the posterior aspects of the metaphysis and diaphysis of samples loaded at the highest duration and frequency (Fig. 7, black arrows).

A greater number of proliferating cells positively expressing $\mathrm{pHH} 3$ were associated with longer

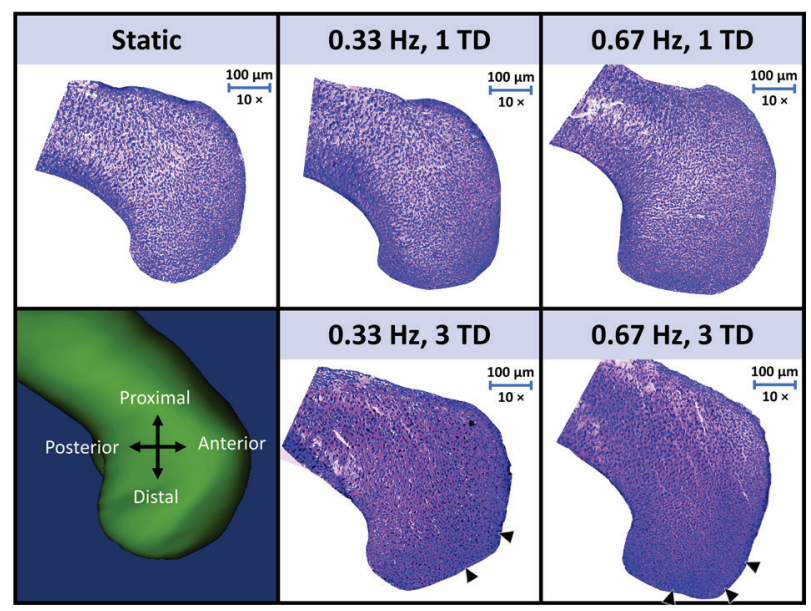

Fig. 6. Increased GAG deposition is associated with loading duration, but not with loading frequency. Increased GAG was detected throughout the lateral condyles of limbs exposed to the longest loading durations (3TD) compared to shorter durations (1TD) and static controls, whereas altering loading frequency had no clear effect on GAG synthesis. Black arrows indicate regions of high GAG synthesis located at the articulating surfaces (anterior distal aspects) of the condyle. Histological assessment of GAG was assessed using toluidine blue staining for select loading groups; static control limbs, dynamic loading with LF, 1TD and 3TD, and HF 1TD and 3TD. loading duration regimes (loaded 3TD) compared to shorter regimes (loaded 1TD), but this was not statistically validated due to having only 1 sample per group (Fig. 8). In contrast, there was no clear effect of varying frequency on proliferation (Fig. 8 ). The distribution of proliferating cells was sparse and scattered with no clear localisation, which is consistent with the previous findings in chick epiphyseal cartilage (Chandaria et al., 2016).

\section{Diaphyseal mineralisation is enhanced by loading duration and frequency}

Almost all movement regimes had an effect on the extent of femora and tibiotarsal diaphyseal mineralisation as compared to static samples, which mostly lacked any mineralised tissue (Fig. 9). The duration of movements applied had a potent effect on the extent of femoral mineralisation, revealing significant effects with every additional step of duration (Table 3). There was an average 3 -fold increase in mineralised tissue in rudiments loaded 3TD relative to 1TD (Fig. 9a $\mathbf{a}_{\mathrm{i}}$ ). Tibiotarsal mineralisation was also responsive to duration but only at 3TD (Table 3 ), showing a significant 2 -fold increase between samples loaded 3TD compared to just 1TD (Fig. 9 $\mathbf{b}_{\mathbf{i}}$ ).

There was a significant independent effect of frequency on femur mineralisation (Table 2), whereby mineralisation had advanced 1.5-fold on average in samples loaded at the higher frequency (Fig. 9 $\mathbf{a}_{\mathrm{ii}}$ ). This trend was also found with tibiotarsal

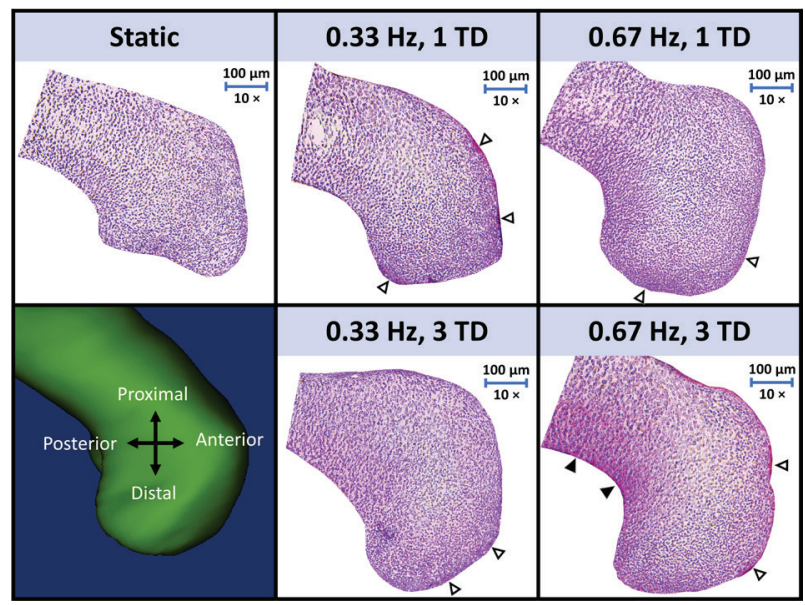

Fig. 7. Epiphyseal collagen deposition was not affected by variations in loading regime. Denser collagen in the articulating surfaces and perichondrium (hollow arrows) was present in the dynamic limbs compared to the static controls. While loading regime had no clear effects on collagen in the lateral condyle epiphyses, collagen deposition increased in the posterior metaphysis and diaphysis in the samples loaded at the longest duration and frequency $(0.67 \mathrm{~Hz}, 3 \mathrm{TD})$, black arrows. Histological assessment of collagen was assessed with picrosirius red staining for select loading groups; static control limbs, dynamic loading with LF, 1TD and 3TD, and HF 1TD and 3TD. 
mineralisation, with also an average 1.5-fold increase, though this result was not statistically significant (Table 2, Fig. 9 $\mathbf{b}_{\mathrm{ij}}$ ). Taken together, bone formation appears to be positively influenced independently by both frequency and duration of stimulation.

There is limited interplay between frequency and duration on cartilage growth or mineralisation

The 2-way ANOVA revealed that there were no significant interactions between frequency and duration effects for both mineralisation measurements, and for all but one cartilage growth measurement, the medial condyle width (Table 2). For all other measurements, the effect of movement duration on cartilage growth and bone mineralisation did not statistically depend on frequency, and vice versa. For the single significant interaction, an interaction-contrast test revealed that the mean medial condyle width, under LF, was $37.5 \%$ greater in the 3TD group compared to the 1TD group. However, under HF, the medial condyle width was $6.8 \%$ lower in in the 3TD group compared to the 1TD group. This indicates that as the frequency applied was switched from LF to HF, the positive effect of loading duration on medial condyle width growth was reversed. However, neither frequency nor duration had any significant effects on medial condyle width when assessed individually (Table 2) which indicated that this particular measurement was not heavily dependent on mechanical loading.

Table 2. Two-way ANOVA $p$-values for testing of the interaction effects or independent (main) effects of loading frequency and duration on joint cartilage feature growth and diaphysis mineralisation. The growth of four cartilage joint features and two mineralisation measurements were significantly affected by loading duration, and one mineralisation measurement by loading frequency.

\begin{tabular}{|c|c|c|c|c|c|c|c|c|c|c|}
\hline & \multicolumn{3}{|c}{ Lateral condyle } & \multicolumn{3}{c|}{ Medial condyle } & \multicolumn{2}{c|}{ Tibiotarsus } & \multicolumn{3}{c|}{ Mineralisation } \\
\cline { 2 - 11 } Statistic & Width & Height & Depth & Width & Height & Depth & Width & Depth & Femur & Tibiotarsus \\
\hline Frequency & - & - & - & - & - & - & - & - & $<0.05$ & - \\
\hline Duration & $<0.05$ & $<0.001$ & - & - & $<0.05$ & - & - & $<0.001$ & $<0.001$ & $<0.05$ \\
\hline Interaction & - & - & - & $<0.05$ & - & - & - & - & - & - \\
\hline
\end{tabular}

Table 3. Bonferroni-adjusted $p$-values of pairwise comparisons between duration and frequency group measurements that exhibited a significant independent effect in the ANOVA. The 4 cartilage features and 2 mineralisation measurements significantly affected by loading duration were most influenced when loaded 3TD compared to just 1TD. Only femur mineralisation was affected by altering loading frequency.

\begin{tabular}{|c|c|c|c|c|c|c|}
\hline Comparison & $\begin{array}{c}\text { Lateral condyle } \\
\text { width }\end{array}$ & $\begin{array}{c}\text { Lateral condyle } \\
\text { height }\end{array}$ & $\begin{array}{c}\text { Medial condyle } \\
\text { height }\end{array}$ & $\begin{array}{c}\text { Tibiotarsal } \\
\text { depth }\end{array}$ & $\begin{array}{c}\text { Femur } \\
\text { mineral }\end{array}$ & $\begin{array}{c}\text { Tibiotarsus } \\
\text { mineral }\end{array}$ \\
\hline 1TD - 2TD & - & - & - & - & $<0.05$ & - \\
\hline 2TD - 3TD & - & $<0.05$ & - & $<0.01$ & $<0.05$ & - \\
\hline 1TD - 3TD & $<0.05$ & $<.001$ & $<0.05$ & $<0.001$ & $<0.001$ & $<0.05$ \\
\hline LF - HF & - & - & - & - & $<0.05$ & - \\
\hline
\end{tabular}
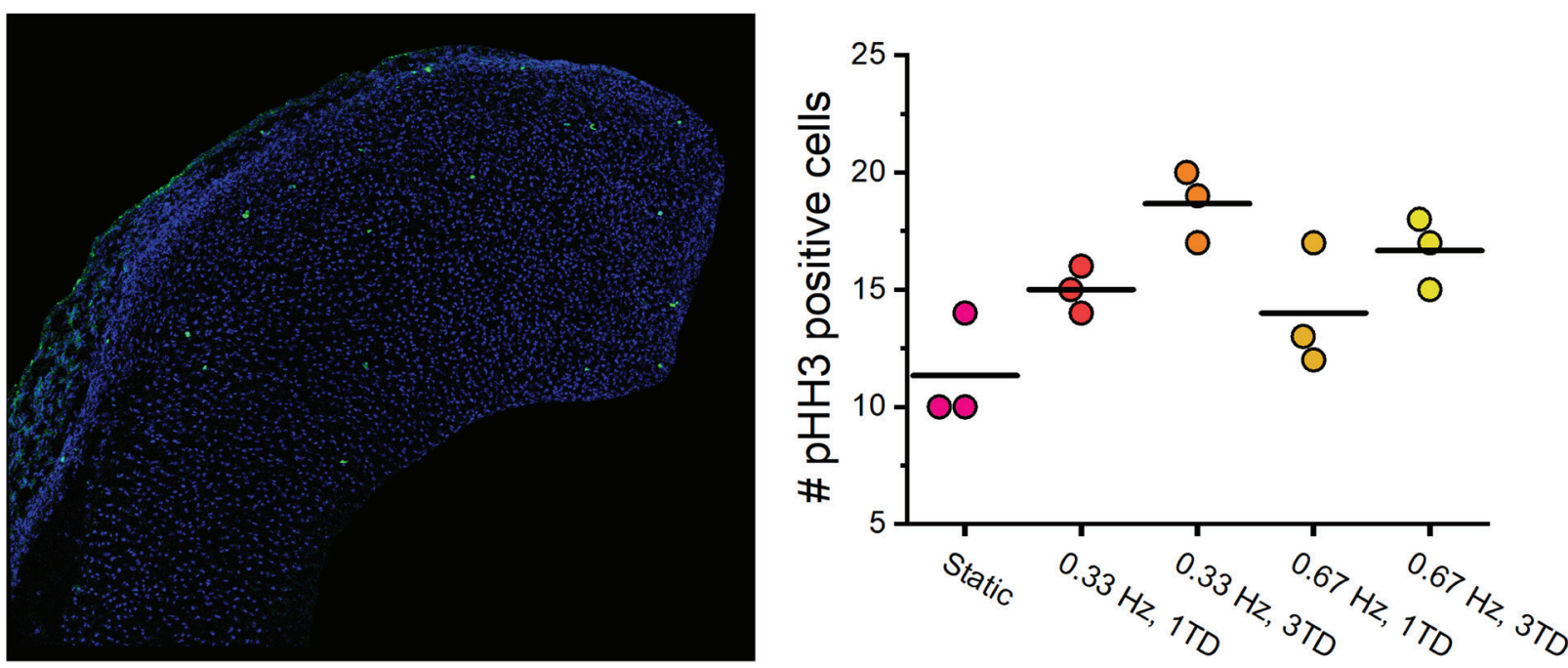

Fig. 8. A higher number of proliferating cells correlated with longer loading durations. The distribution of proliferating cells was sparse and scattered throughout the condyle. Quantification of cells positively expressing mitosis marker phospho-Histone $\mathrm{H} 3$ across three sections of the lateral condyle of select loading groups ( $n=1$ per group); static control limbs, dynamic loading with LF, 1TD and 3TD, and HF 1TD and 3TD. 


\section{Discussion}

In this study, movement regimes were applied to embryonic chick hindlimb explants in vitro to quantify the effects of varying loading frequency and duration on chondrogenesis and mineralisation. Increasing movement duration promoted joint cartilage growth and mineralisation in a dose-dependent manner. However, while increasing loading frequency had a significant positive effect on mineralisation, altering frequency within the ranges examined had no influence on cartilage growth or shaping. Thus, the hypothesis that both frequency and duration of cyclic flexion loading would enhance chondrogenesis and ossification in a dose-dependent manner was only partially corroborated. Furthermore, there was no consistent interaction found between the effects of movement frequency and duration on cartilage or bone measurements, rejecting the secondary hypothesis that frequency and duration would synergistically promote cartilage and bone formation. Although the data were limited, histological evaluation and cell proliferation quantification suggested that GAG deposition and proliferation may have contributed to the duration-based effects on femoral cartilage growth, while limited variation in collagen deposition was detected in the epiphyses of loaded limbs. This builds on earlier work employing the same in vitro model, indicating that an optimum movement magnitude is able to promote cartilage growth and proliferation when compared to underand over-flexion movements (Chandaria et al., 2016). Together, the combined results provided evidence that biomechanical parameters can selectively enhance the formation of developing cartilage and bone in vitro.

The four cartilage shape measurements significantly affected by loading duration were lateral condyle height and width, medial condyle height and proximal tibiotarsal depth. Longer duration of loading also led to extended posterior protrusions in the femoral condyles and the tibiotarsal plateau, as well as denser GAG matrix localised to the articulating surfaces of the lateral condyle. Given the
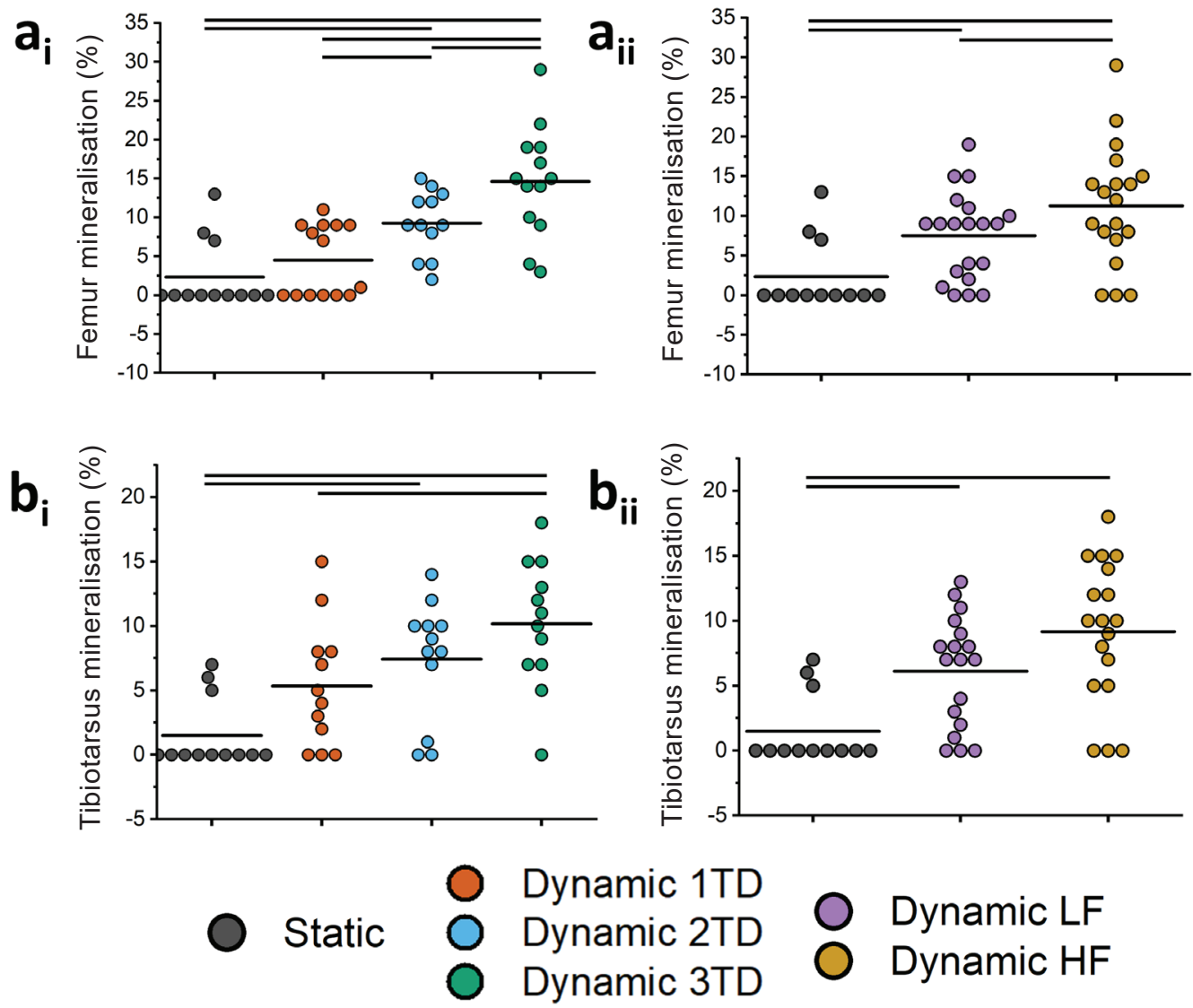

Fig. 9. Bone mineralisation was promoted by increasing loading duration and frequency. The extent of femoral mineralisation was significantly promoted by increasing duration $\left(\mathbf{a}_{\mathrm{i}}\right)$ and frequency $\left(\mathbf{a}_{\mathrm{ii}}\right)$ of applied flexion-extension movements, whereas tibiotarsal mineralisation was only significantly enhanced when exposed to longer durations $\left(\mathbf{b}_{\mathbf{i}}\right)$. Comparison of mineralisation measurements as analysed in the two-way ANOVA (Table 2), pooled according to loading duration groups $\left(\mathbf{a}_{\mathrm{i}}-\mathbf{b}_{\mathrm{i}}\right)$ loading frequency groups $\left(\mathbf{a}_{\mathrm{ii}}-\mathbf{b}_{\mathrm{ii}}\right)$, with static cultured samples for comparison (static, grey). Duration groups include samples dynamically loaded for $2 \mathrm{~h}$ periods 1TD (orange), 2TD (blue) or 3TD (green) $\left(\mathbf{a}_{\mathrm{i}}-\mathbf{b}_{\mathrm{i}}\right)$. Loading frequency groups include samples dynamically loaded at LF (purple) or HF (gold) $\left(\mathbf{a}_{\mathrm{ii}}-\mathbf{b}_{\mathrm{ii}}\right)$. Central bars represent group means and bars above represent significant differences between groups $(p<0.05)$. 
specific variations in shape and ECM synthesis, it is likely that selective regions of the joint surfaces are loaded more than others during articulation during the stage of development (starting at embryonic day 7) analysed in this study. The early (HH30/31) chick medial femoral condyle articulates with the tibiotarsus and lateral condyle with the fibula (Roddy et al., 2009), suggesting that both condyles would experience mechanical loading during knee flexionextension movements. It is proposed that the cartilage regions showing the greatest effects of increased duration of loading are the areas of greatest contact during articulation in a predominantly flexed knee position.

The significant effects on cartilage growth of duration, but not frequency, were consistent with the indicative relationship between duration of loading and increased epiphyseal GAG deposition and cell proliferation. As GAGs appeared most concentrated in the highest duration groups, and also at the articulating surfaces, GAG synthesis may play a key role in mechanoregulation of embryonic cartilage growth and morphogenesis. The trend of increased proliferation with longer loading durations indicated another potential mechanism through which duration of loading promotes cartilage growth. However, the involvement of proliferation in morphogenesis at the examined stage of development is less clear, since the proliferating cells were sparsely scattered throughout the lateral condyle. While limited variation in collagen synthesis between loading groups was observed in the femoral epiphyses, the increased collagen density localised to the posterior metaphysis and distal diaphysis in limbs loaded with a long duration and high frequency may be reflective of increased stimuli in this region during flexioninduced loading. Immunofluorescence imaging of specific collagen networks such as collagen II that emerge during cartilage development (Ahmed and Nowlan, 2020) may better highlight the influence of loading frequency and duration on collagen synthesis and organisation in articular regions of cartilage.

Several groups have explored the effects of varying equivalent loading parameters on chondrogenesis in cell-based studies. With regards to loading duration, chick limb bud cells (HH stage 24/25) embedded in gels exposed to cyclic loading at $0.33 \mathrm{~Hz}$ for $8 \mathrm{~d}$ exhibit increased GAG synthesis and elevated cartilage nodule densities when exposed to cyclic compression loading for 54 or 120 min per day, compared to just $12 \mathrm{~min}$ (Elder et al., 2001). However, at $120 \mathrm{~min}$, GAG synthesis starts to decline, suggesting the optimal duration is under $2 \mathrm{~h}$ for limb bud cells in gels. Chen et al. (2018) and Smith et al. (2000), employing chondrocyte-seeded gels, observed that chondrocytic type II collagen mRNA expression and synthesis peaks with 3 or $4 \mathrm{~h}$ of $1 \mathrm{~Hz}$ mechanical stimulation per day, while Chen et al. (2018) found aggrecan mRNA expression also peaks at $3 \mathrm{~h}$. In contrast Smith et al. (2000) found that increasing loading duration continues to promote aggrecan expression up to
$12 \mathrm{~h}$ a day before reaching a plateau at durations exceeding $12 \mathrm{~h}$. The contrasting outcomes in terms of optimal loading duration between these studies and the present one is likely primarily related to the use of whole tissues as opposed to cells, and may also be related to the differences in the method of applied mechanical stimulation, type of cell or cell construct, as well as the stable frequency applied.

A novel finding from this study was that modulating movement frequency, within the ranges examined, did not affect chondrogenesis. This contradicted an earlier finding of a positive linear relationship between GAG deposition and lower cyclic compression frequencies of between 0.03 and $0.33 \mathrm{~Hz}$ applied to chick limb bud cells in gels (Elder et al., 2001). However, that study was focussed on differentiation (an earlier stage than the present study). Furthermore, they found no statistical differences between 0.15 and $0.33 \mathrm{~Hz}$, which may indicate that a larger step in frequency is required to stimulate observable differences in the sub-1 $\mathrm{Hz}$ range, given this present study's findings. Other chondrocyte-construct studies, comparing a frequency range of $0.3-3 \mathrm{~Hz}$ applied through cyclic loading, found that $1 \mathrm{~Hz}$ is the lowest frequency needed for enhancing GAG mRNA expression or synthesis compared to static controls, and higher frequencies had either no additional effect, or - in two cases - a negative effect (Lee and Bader, 1997; Lin et al., 2014; Shelton et al., 2003; Tsuang et al., 2008). Furthermore, cell proliferation has been shown to increase compared to static controls when exposed to the higher frequencies of 2-3 Hz (Shelton et al., 2003; Tsuang et al., 2008), whereas varying frequencies in the range $0.5-2 \mathrm{~Hz}$ has no effect on cell numbers (Lin et al., 2014). It is therefore possible that higher ranges of movement frequency than those examined in this study may be necessary to sufficiently alter the rates of proliferation or matrix synthesis to modulate cartilage growth.

The positive effects of loading duration and frequency on femoral and tibiotarsal mineralisation supports earlier experimental animal work highlighting the importance of biophysical stimuli in bone development (reviewed in Nowlan, 2015). Research on the effect of applied loading duration on bone formation in whole limbs tend to use timescales of the order of minutes and thus are not directly comparable with the current duration results. However, prolonging loading duration from under $1 \mathrm{~min}$ to $5 \mathrm{~min}$ per day has been shown to enhance bone formation of rat tibiae exposed to cyclic bending (Turner et al., 1994) or compression (Yang et al., 2017). Cell-based studies have found that cyclic mechanical stretching of MSCs for a continuous period of $6 \mathrm{~h}$ elicits a significant upregulation of alkaline phosphatase activity and osteogenic gene expression markers bone morphogenic protein 2, runt-related transcription factor 2 (Runx-2) and osteocalcin compared to those loaded for 17 min (Yang et al., 2010) or $2 \mathrm{~h}$ (Grottkau et al., 2013). Furthermore, the expression of osteogenic 
markers Runx-2, cyclooxygenase-2 and osteopontin is increased in MSCs exposed to $4 \mathrm{~h}$ compared to $2 \mathrm{~h}$ of shear stress, through oscillatory fluid flow. These findings depended on the frequency and magnitude of stress (Stavenschi et al., 2017). The earlier and present findings together imply that differentiation into osteoblasts and subsequent mineral deposition can be modulated during endochondral ossification by optimising the applied loading duration. The current finding that increasing movement frequency from 0.33 to $0.67 \mathrm{~Hz}$ led to enhanced femoral mineralisation indicates that frequency upregulates the osteogenic response of diaphyseal tissue undergoing endochondral ossification. This is supported by the work of Henstock et al. (2013), who found that frequencies of hydrostatic pressure in the range $0.005-2 \mathrm{~Hz}$, applied over $14 \mathrm{~d}$, significantly correlated with larger and denser diaphyseal mineralisation in in vitro cultured chick fetal femora. The positive effect of loading frequency on bone formation rate is also found in adult rat ulna subjected to cyclic axial compressions and is observable up to $10 \mathrm{~Hz}$ (Hsieh and Turner, 2001).

To improve the biomechanical function of engineered skeletal tissues, some established empirical concepts of developmental biology have been incorporated into construct design to recapitulate (to some degree) the natural mechanisms that control tissue formation (Lenas et al., 2009). Integrating concepts such as semi-autonomy of intermediate tissue forms that sequentially appear during tissue development has been a successful initiative for 3D models of cartilage development and endochondral ossification (Farrell et al., 2011; Foster et al., 2015; Freeman et al., 2015a; Freeman et al., 2015b; Jukes et al., 2008; Quintana et al., 2009; Scotti et al., 2010; Sheehy et al., 2013). With mounting evidence for the integral role of mechanobiological processes in regulating induction, differentiation and patterning events in musculoskeletal development (Arvind and Huang, 2017), applying biomechanical cues to developmentally inspired constructs may be critical to advancing current successes. Furthermore, recent evidence suggests that in vitro models of biochemically induced endochondral ossification can be enhanced by introducing mechanical stimulation (Freeman et al., 2017). The outcomes from the current study suggest that it is possible to optimise mechanical stimulation to differentially promote the biological events responsible for cartilage and bone formation through developmental processes. Establishment of the plateau of the effects of these loading parameters on tissue formation, extrapolation and then incorporation of the biomechanical regimes into tissue construct designs will be valuable for developmental engineering initiatives and ultimately clinical utility.

This study was not without its limitations. As several studies found frequencies at or above $1 \mathrm{~Hz}$ to be optimal for cartilage ECM synthesis or proliferation (Lee and Bader, 1997; Lin et al., 2014;
Shelton et al., 2003; Tsuang et al., 2008), it would have been valuable to have explored movement frequencies above $0.66 \mathrm{~Hz}$ to determine if loading frequency is also redundant for chondrogenesis and effective for increased bone formation at higher frequencies. However, constraints of the bioreactor equipment limited the choice of frequency. Additionally, only a single stage of development was assessed, a narrow representation of the overall processes that lead to skeletal tissue maturation. Frequency and duration of stimulation may have altered effects in earlier or subsequent stages due to the importance of timing in patterning during skeletogenesis, which calls for further investigation of these effects in other stages to fine tune these parameters as developmental engineering models progress. The mineralisation analysis was compromised due to poor retention of the alizarin red stain during preparation for 3D imaging. The same issues are not present for cultured mouse limbs, and therefore future work investigating the effect of loading on aspects of mineralisation such as volume and bone collar shape will preferentially use the mouse model system. Finally, sample numbers were very low for the histological and proliferation analyses. Future studies are needed to investigate the matrix and cell level events underlying the mechanically-driven changes observed in the current study.

In conclusion, the current study demonstrated the efficacy of two biomechanical parameters, loading frequency and duration, in promoting developing cartilage and bone formation events. The results have implications for developmental engineering strategies aiming to mediate the formation of intermediary tissues, as they suggest formation of cartilage and bone differs in response to biophysical stimuli. Integration of biomechanical loading regimes with developmentally inspired tissue engineering strategies will aid generation of functional tissues that can be clinically suitable for tissue repair and regenerative interventions.

\section{Acknowledgements}

We would like to thank Ms Zoë Despature for her support with the generation of 3D models for analysis. This research was funded by the European Research Council under the European Union's Seventh Framework Programme (ERC Grant agreement number 336306). The funders had no role in study design, data collection, analysis, decision to publish or preparation of the manuscript.

\section{References}

Ahmed S, Nowlan NC (2020) Initiation and emerging complexity of the collagen network during prenatal skeletal development. Eur Cell Mater 39: 136-155. 
Amini AR, Laurencin CT, Nukavarapu SP (2012) Bone tissue engineering: recent advances and challenges. Crit Rev Biomed Eng 40: 363-408.

Arvind V, Huang AH (2017) Mechanobiology of limb musculoskeletal development. Ann N Y Acad Sci 1409: 18-32.

Brunt LH, Norton JL, Bright JA, Rayfield EJ, Hammond CL (2015) Finite element modelling predicts changes in joint shape and cell behaviour due to loss of muscle strain in jaw development. J Biomech 48: 3112-3122.

Chandaria VV, McGinty J, Nowlan NC (2016) Characterising the effects of in vitro mechanical stimulation on morphogenesis of developing limb explants. J Biomech 49: 3635-3642.

Chen CH, Kuo CY, Chen JP (2018) Effect of cyclic dynamic compressive loading on chondrocytes and adipose-derived stem cells co-cultured in highly elastic cryogel scaffolds. Int J Mol Sci 19: 370. DOI: 10.3390/ijms19020370.

Choi JR, Yong KW, Choi JY (2018) Effects of mechanical loading on human mesenchymal stem cells for cartilage tissue engineering. J Cell Physiol 233: 1913-1928.

Elder SH, Goldstein SA, Kimura JH, Soslowsky LJ, Spengler DM (2001) Chondrocyte differentiation is modulated by frequency and duration of cyclic compressive loading. Ann Biomed Eng 29: 476-482.

Farrell E, Both SK, Odorfer KI, Koevoet W, Kops $\mathrm{N}$, O'Brien FJ, de Jong RJB, Verhaar JA, Cuijpers V, Jansen J, Erben RG, van Osch G (2011) In-vivo generation of bone via endochondral ossification by in-vitro chondrogenic priming of adult human and rat mesenchymal stem cells. BMC Musculoskelet Disord 12: 31. DOI: 10.1186/1471-2474-12-31.

Foster NC, Henstock JR, Reinwald Y, El Haj AJ (2015) Dynamic 3D culture: models of chondrogenesis and endochondral ossification. Birth Defects Res C Embryo Today 105: 19-33.

Freeman FE, Allen AB, Stevens HY, Guldberg RE, McNamara LM (2015a) Effects of in vitro endochondral priming and pre-vascularisation of human MSC cellular aggregates in vivo. Stem Cell Res Ther 6: 218. DOI: 10.1186/s13287-015-0210-2.

Freeman FE, Haugh MG, McNamara LM (2015b) An in vitro bone tissue regeneration strategy combining chondrogenic and vascular priming enhances the mineralization potential of mesenchymal stem cells in vitro while also allowing for vessel formation. Tissue Eng Part A 21: 1320-1332.

Freeman FE, McNamara LM (2017) Endochondral priming: a developmental engineering strategy for bone tissue regeneration. Tissue Eng Part B Rev 23: 128-141.

Freeman FE, Schiavi J, Brennan MA, Owens P, Layrolle P, McNamara LM (2017) Mimicking the biochemical and mechanical extracellular environment of the endochondral ossification process to enhance the in vitro mineralization potential of human mesenchymal stem cells. Tissue Eng Part A 23: 1466-1478.
Grottkau BE, Yang XM, Zhang L, Ye L, Lin YF (2013) Comparison of effects of mechanical stretching on osteogenic potential of ASCs and BMSCs. Bone Res 1: 282-290.

Henstock JR, Rotherham M, Rose JB, El Haj AJ (2013) Cyclic hydrostatic pressure stimulates enhanced bone development in the fetal chick femur in vitro. Bone 53: 468-477.

Hsieh YF, Turner CH (2001) Effects of loading frequency on mechanically induced bone formation. J Bone Miner Res 16: 918-924.

Jukes JM, Both SK, Leusink A, Sterk LMT, Van Blitterswijk CA, De Boer J (2008) Endochondral bone tissue engineering using embryonic stem cells. Proc Natl Acad Sci U S A 105: 6840-6845.

Kahn J, Shwartz Y, Blitz E, Krief S, Sharir A, Breitel DA, Rattenbach R, Relaix F, Maire P, Rountree RB, Kingsley DM, Zelzer E (2009) Muscle contraction is necessary to maintain joint progenitor cell fate. Dev Cell 16: 734-743.

Khaliduzzaman A, Fujitani S, Kondo N, Ogawa Y, Fujiura T, Suzuki T, Kashimori A, Syduzzaman MD, Rahman A (2019) Non-invasive characterization of chick embryo body and cardiac movements using near infrafred light. Eng Agric Environ Food 12: 32-39.

Lee DA, Bader DL (1997) Compressive strains at physiological frequencies influence the metabolism of chondrocytes seeded in agarose. J Orthop Res 15: 181-188.

Lenas P, Moos M, Luyten FP (2009) Developmental engineering: a new paradigm for the design and manufacturing of cell-based products. Part I: from three-dimensional cell growth to biomimetics of in vivo development. Tissue Eng Part B Rev 15: 381-394.

Levillain A, Rolfe RA, Huang Y, Iatridis JC, Nowlan NC (2019) Short-term fetal immobility temporally and progressively affects chick spinal curvature and anatomy and rib development. Eur Cell Mater 37: 23-41.

Lin WY, Chang YH, Wang HY, Yang TC, Chiu TK, Huang SB, Wu MH (2014) The study of the frequency effect of dynamic compressive loading on primary articular chondrocyte functions using a microcell culture system. Biomed Res Int 2014: 762570. DOI: 10.1155/2014/762570.

Natenstedt J, Kok AC, Dankelman J, Tuijthof GJ (2015) What quantitative mechanical loading stimulates in vitro cultivation best? J Exp Orthop 2: 15. DOI: 10.1186/s40634-015-0029-x.

Nowlan NC (2015) Biomechanics of fetal movement. Eur Cell Mater 29: 1-21.

Nowlan NC, Bourdon C, Dumas G, Tajbakhsh S, Prendergast PJ, Murphy P (2010a) Developing bones are differentially affected by compromised skeletal muscle formation. Bone 46: 1275-1285.

Nowlan NC, Sharpe J, Roddy KA, Prendergast PJ, Murphy P (2010b) Mechanobiology of embryonic skeletal development: insights from animal models. Birth Defects Res C Embryo Today 90: 203-213.

Parisi C, Chandaria VV, Nowlan NC (2018) Blocking mechanosensitive ion channels eliminates 
the effects of applied mechanical loading on chick joint morphogenesis. Philos Trans R Soc Lond B Biol Sci 373: 20170317. DOI: 10.1098/rstb.2017.0317.

Perez JR, Kouroupis D, Li DJ, Best TM, Kaplan L, Correa D (2018) Tissue engineering and cell-based therapies for fractures and bone defects. Front Bioeng Biotechnol 6: 105. DOI: 10.3389/fbioe.2018.00105.

Quintana L, Sharpe J (2011) Optical projection tomography of vertebrate embryo development. Cold Spring Harb Protoc 2011: 586-594.

Quintana L, zur Nieden NI, Semino CE (2009) Morphogenetic and regulatory mechanisms during developmental chondrogenesis: new paradigms for cartilage tissue engineering. Tissue Eng Part B Rev 15: 29-41.

Roddy KA, Nowlan NC, Prendergast PJ, Murphy P (2009) 3D representation of the developing chick knee joint: a novel approach integrating multiple components. J Anat 214: 374-387.

Roddy KA, Prendergast PJ, Murphy P (2011) Mechanical influences on morphogenesis of the knee joint revealed through morphological, molecular and computational analysis of immobilised embryos. PLoS One 6: e17526. DOI: 10.1371/journal.pone.0017526.

Rolfe R, Roddy K, Murphy P (2013) Mechanical regulation of skeletal development. Curr Osteoporos Rep 11: 107-116.

Salinas EY, Hu JC, Athanasiou K (2018) A guide for using mechanical stimulation to enhance tissueengineered articular cartilage properties. Tissue Eng Part B Rev 24: 345-358.

Scotti C, Tonnarelli B, Papadimitropoulos A, Scherberich A, Schaeren S, Schauerte A, Lopez-Rios J, Zeller R, Barbero A, Martin I (2010) Recapitulation of endochondral bone formation using human adult mesenchymal stem cells as a paradigm for developmental engineering. Proc Natl Acad Sci U S A 107: 7251-7256.

Sharpe J, Ahlgren U, Perry P, Hill B, Ross A, Hecksher-Sorensen J, Baldock R, Davidson D (2002) Optical projection tomography as a tool for 3D microscopy and gene expression studies. Science 296: 541-545.

Sheehy EJ, Vinardell T, Buckley CT, Kelly DJ (2013) Engineering osteochondral constructs through spatial regulation of endochondral ossification. Acta Biomater 9: 5484-5492.

Shelton JC, Bader DL, Lee DA (2003) Mechanical conditioning influences the metabolic response of cell-seeded constructs. Cells Tissues Organs 175: 140-150.

Smith RL, Lin J, Trindade MCD, Shida J, Kajiyama G, Vu T, Hoffman AR, van der Meulen MCH, Goodman SB, Schurman DJ, Carter DR (2000) Time-dependent effects of intermittent hydrostatic pressure on articular chondrocyte type II collagen and aggrecan mRNA expression. J Rehabil Res Dev 37: 153-161.

Sotiriou V, Rolfe RA, Murphy P, Nowlan NC (2019) Effects of abnormal muscle forces on prenatal joint morphogenesis in mice. J Orthop Res 37: 22872296.

Stavenschi E, Labour MN, Hoey DA (2017) Oscillatory fluid flow induces the osteogenic lineage commitment of mesenchymal stem cells: the effect of shear stress magnitude, frequency, and duration. J Biomech 55: 99-106.

Tsuang YH, Lin YS, Chen LT, Cheng CK, Sun JS (2008) Effect of dynamic compression on in vitro chondrocyte metabolism. Int J Artif Organs 31: 439449.

Turner CH, Forwood MR, Otter MW (1994) Mechanotransduction in bone - do bone-cells act as sensors of fluid flow. FASEB J 8: 875-878.

Usami K, Mizuno H, Okada K, Narita Y, Aoki M, Kondo T, Mizuno D, Mase J, Nishiguchi H, Kagami H, Ueda M (2009) Composite implantation of mesenchymal stem cells with endothelial progenitor cells enhances tissue-engineered bone formation. J Biomed Mater Res A 90: 730-741.

Watson SJ, Bekoff A (1990) A kinematic analysis of hindlimb motility in 9- and 10-day-old chick embryos. J Neurobiol 21: 651-660.

Yang HS, Embry RE, Main RP (2017) Effects of loading duration and short rest insertion on cancellous and cortical bone adaptation in the mouse tibia. PLoS One 12: e0169519. DOI: 10.1371/journal. pone.0169519.

Yang XM, Gong P, Lin YF, Zhang LR, Li XY, Yuan QA, Tan Z, Wang YY, Man Y, Tang H (2010) Cyclic tensile stretch modulates osteogenic differentiation of adipose-derived stem cells via the BMP-2 pathway. Arch Med Sci 6: 152-159.

\section{Discussion with Reviewers}

Stephen Thorpe: The authors have seen an increase in cartilage development with increasing rounds/ time of loading. Does the authors' understanding of the system suggest that continual loading would provide the best outcome, or is there a developmental requirement for both periods of loading and periods of rest?

Authors: Previous experimental cell and animal limb loading studies have found that the chondrogenic and osteogenic responses to externally applied loading saturates, leading to desensitisation of cellular mechanosensitivity. Insertion of shortterm rest intervals between loading bouts has been found to potently enhance cartilage cell biosynthesis (Chowdhury et al., 2003, additional reference) and bone formation (Robling et al., 2002, additional reference), highlighting the importance of a 'recovery period' from loading for optimal mechanotransduction signalling. From this prior literature it can be speculated that the periods of inactivity during skeletal development may be important; however, the refractory period and optimal recovery periods for development have not 
been documented. During chick embryogenesis, movements occur during periodic episodes of activity and inactivity (Watson and Bekoff, 1990; Khaliduzzamana et al., 2019). It may be beneficial to learn the importance of rest periods for critical events in cartilage and bone development to improve the outcomes of developmental engineering strategies which aim to recapitulate these processes. Future avenues for this research include using the authors' bioreactor system to investigate the potential influence of desensitisation on chondrogenesis and ossification by implementing loading regimes that eliminated rest periods between loading bouts (e.g. $6 \mathrm{~h}$ continual loading versus $3 \times 2 \mathrm{~h}$ loading bouts).

Oliver Gardner: The authors highlight the recapitulation of the highly organised structure of native tissue and mechanical properties sufficient to successfully bear full bodyweight for the lifetime of the recipient as key challenges to be overcome in producing functional cartilage and bone constructs. Can the authors comment on how this study moves us closer to overcoming these challenges?

Authors: The formation of the highly organised tissue structures in cartilage and bone during development depends on a multitude of cell signalling events that occur in sequence and interact, orchestrating the progression of tissue growth, cell differentiation and extracellular matrix synthesis. Developmental engineering strategies aim to recapitulate aspects of these developmental processes as a means of producing organised and functional tissues in vitro (Lenas et al., 2009; Quintana et al., 2009; Freeman and McNamara, 2017). These strategies sometimes focus on mimicking the biochemical processes of developmental events, without fully considering the physical environment. Since physical stimuli arising from movement are critical in guiding skeletal development (reviewed in Nowlan, 2015), it may be beneficial to identify and incorporate the optimal mechanical signals for chondrogenesis and ossification, such as that investigated within this study, into developmentally-inspired tissue constructs. Findings from the present study suggest that aspects of chondrogenesis and ossification are differentially affected by the same biophysical stimuli. One way in which this knowledge can potentially be leveraged is to tailor mechanical loading regimes to selectively enhance formation of cartilage, bone or intermediate tissues in vitro, which may improve control over tissue development in developmentallyinspired tissue constructs.

Oliver Gardner: The observed increases in cartilage surface growth and mineralisation have not plateaued with increasing loading duration, suggesting that further increasing loading incidence may lead to further improvements in tissue development. However, as incidence is increased, the unloaded time between loading sessions is reduced, which may limit the benefits of further loading bouts due to desensitisation of the tissue to applied load. Can the authors comment on the importance of rest periods between loading bouts in this context?

Authors: The importance of rest periods is an important consideration, as also highlighted in a question from the previous reviewer. In an earlier study, it was demonstrated that increasing the amount of movement (degree of flexion) beyond a physiological range did not have positive effects (Chandaria et al., 2016). However, in the current study "plateaus" in cartilage or bone response to either frequency or duration were not reached. As the current study's maximum duration was $6 \mathrm{~h}$ per day, there is certainly scope in future studies to increase the duration further while still including substantial rest periods (e.g. $2 \mathrm{~h}$ loading, $2 \mathrm{~h}$ rest), and this is a promising avenue for future studies.

Gwendolen Reilly: As well your work on the overall shape of the nascent bones it would be really interesting to know if there are microscale changes within the matrix e.g. matrix re-orientation in response to load, given the specific organisational structure of different regions of the condyle. Do you have any plans to look at these samples or similar ones using histology or SHG microscopy to localise proteoglycans and collagen fibres, including examining directionality?

Authors: To understand the influence of loading on microscale changes occurring in the matrix, spare samples ( $n=1-2$ from each experimental group) were sectioned and stained with both toluidine blue and picrosirius red to visualise localisation of GAGs and collagen in the lateral condyle, respectively. Unfortunately, the work was limited to histology due to the lack of samples and it was not possible to investigate matrix fibre orientation using techniques such as SHG microscopy. This is a great suggestion for future work as correct matrix orientation is critical to cartilage function, yet still a major challenge to replicate in vitro. It would be beneficial to identify the optimal loading regime for improving this property in developmentally-inspired cartilage constructs.

\section{Additional References}

Chowdhury TT, Bader DL, Shelton JC, Lee DA (2003) Temporal regulation of chondrocyte metabolism in agarose constructs subjected to dynamic compression. Arch Biochem Biophys 417: 105-111.

Robling AG, Hinant FM, Burr DB, Turner CH (2002) Improved bone structure and strength after long-term mechanical loading is greatest if loading is separated into short bouts. J Bone Miner Res. 17: 1545-1554.

Editor's note: The Scientific Editor responsible for this paper was Martin Stoddart. 